Western Washington University

Western CEDAR

2001

\title{
Seismicity and Velocity Structure of Loihi Seamount from the 1996 Earthquake Swarm
}

Jacqueline Caplan-Auerbach

Western Washington University, jackie.caplan-auerbach@wwu.edu

F. K. Duennebier

Follow this and additional works at: https://cedar.wwu.edu/geology_facpubs

Part of the Geology Commons, and the Geophysics and Seismology Commons

\section{Recommended Citation}

Caplan-Auerbach, Jacqueline and Duennebier, F. K., "Seismicity and Velocity Structure of Loihi Seamount from the 1996 Earthquake Swarm" (2001). Geology Faculty Publications. 47.

https://cedar.wwu.edu/geology_facpubs/47 


\title{
Seismicity and Velocity Structure of Loihi Seamount from the 1996 Earthquake Swarm
}

\author{
by J. Caplan-Auerbach and F. K. Duennebier
}

\begin{abstract}
The largest earthquake swarm yet recorded on Loihi submarine volcano took place in July and August of 1996. The swarm consisted of two phases of seismic activity and was associated with the formation of a pit crater and additional faulting of Loihi's summit platform. The first phase of activity was comprised of predominantly high-frequency events scattered over the southern flanks of the volcano. Following a day of seismic quiescence, the second phase of activity began, consisting of lower-frequency earthquakes with strong $T$-phases. The phase 2 events took place beneath Loihi's summit, presumably marking the formation of the pit crater, Pele's Pit. Data obtained by an ocean-bottom seismometer (OBS) on Loihi during the swarm help constrain a new velocity model for Loihi. The relocated earthquakes, combined with other characteristics of the swarm, enabled us to develop a model for the events leading up to the formation of Pele's Pit that includes (1) a prolonged eruption, (2) a tectonic event beneath Loihi's south flank, and (3) the drainage of a shallow magma chamber.
\end{abstract}

\section{Introduction}

Loihi seamount is an undersea volcano, the youngest known expression of the Hawaiian hot spot. Located $\sim 65$ $\mathrm{km}$ south of Kilauea caldera (Fig. 1), Loihi rises from a depth of $\sim 5000$ to $\sim 1000$ meters below sea level (mbsl). The name Loihi means long one, a name that reflects the topographic control of north-south trending rift zones on Loihi's morphology (Fig. 2). Two small, north-trending rift zones extend from the northern part of the summit with a longer rift extending to the south.

Loihi has a well-defined summit platform with an average depth of $\sim 1200 \mathrm{mbsl}$. Prior to 1996, the summit platform included two elongated pit craters, East Pit and West Pit (Fig. 2). East Pit has a diameter of $\sim 1200 \mathrm{~m}$ and a base that lies $123 \mathrm{~m}$ below the surrounding summit plateau. West Pit has approximately the same areal extent, but has only 73 $\mathrm{m}$ of relief. Recent high-resolution mapping of the summit area (Smith et al., 1997) shows several flat areas with arcuate boundaries, interpreted as former pit craters, that have since filled with volcanoclastic debris and lava flows. Prior to the 1996 swarm, the southwestern corner of the summit area was occupied by a $\sim 100 \mathrm{~m}$ high cone known as Pele's Peak, the site of long-term, vigorous hydrothermal venting (Malahoff, 1987). Coincident with the 1996 earthquake swarm, Pele's Peak collapsed to form a 600-m wide by 300-m deep pit crater dubbed Pele's Pit. Additional faulting to the west of West Pit and north of the East Pit area was recognized on submersible dives and bathymetric surveys and is also be- lieved to be associated with the 1996 seismic activity (T. Kerby, personal comm., 1996) A narrow depression known as the Sand Channel now connects East Pit and Pele's Pit.

Seismicity has long been detected in the region near Loihi, but was only attributed to that volcano in the early 1960s. Since that time, between 2 and 10 Loihi earthquakes have typically been detected each month by the seismic network of the Hawaii Volcano Observatory (HVO). This background seismicity is punctuated by periodic swarms, wherein tens to hundreds of earthquakes occur on the volcano within a few days (Fig. 3). Since 1959, when Loihi earthquakes were first located by the HVO network, nine earthquake swarms have been detected, and a poorly located swarm in 1952 may also have been associated with Loihi (Klein, 1982). The earthquake swarm of July-August 1996 was the largest yet recorded on Loihi.

In this article we examine the chain of events leading up to the collapse of the Pele's Pit crater. To this end, we first describe the chronology of the 1996 Loihi earthquake swarm and describe how the data collected at HVO and on the OBS enabled us to determine a new velocity model for use with Loihi earthquakes. Use of the new model allowed us to more tightly constrain epicentral locations for the swarm. We use these data, as well as earthquake power spectra, focal mechanisms, and fault dimensions to examine the chain of events leading up to and including the earthquake swarm. 


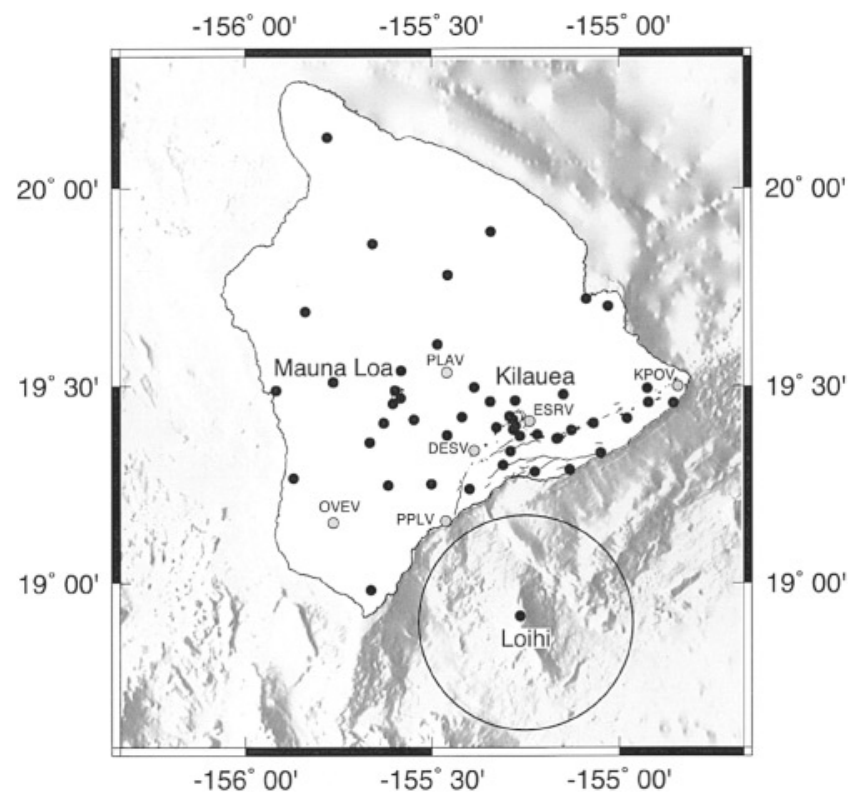

Figure 1. Location of Loihi seamount and Hawaii island. The dots on the Big Island represent seismic stations operated by the Hawaii Volcano Observatory. Seismic stations for which we show waveform or spectral data (Fig. 6 and 7) are shown in gray circles and labeled with station names. The dot on Loihi represents the OBS deployed during the RRC. The circle around Loihi seamount indicates the region in which the Loihi-3 velocity model was used in relocating earthquakes. A 5-km transition zone exists around this area. Klein's (1981) velocity model was used in all other regions.

\section{Chronology of the Earthquake Swarm}

The 1996 earthquake swarm consisted of two phases of activity separated by a day of seismic quiescence. The initial phase began on the evening of 16 July and continued until 18 July (Fig. 4). During this phase, 170 events of $M_{\mathrm{L}}>1$ (the approximate detection threshold) were detected by the HVO network. Seventy of these events were located. The first few hours of activity consisted of events located on Loihi's southwest flank beneath a structure thought to be a failed rift (Fornari et al., 1988). After that time, the epicentral locations appear more scattered over the south flanks of the volcano (Fig. 5). Although depths are poorly constrained because of the location of the earthquakes relative to the HVO sensors, the early events show no apparent trends or clustering in depth. Phase 1 ended on 19 July, when no locatable Loihi earthquakes were detected.

On 20 July, phase 2 of the Loihi seismic activity began, with increased numbers and intensity relative to phase 1 . During the next 10 days, the volcano averaged 400 earthquakes per day, with magnitudes between $M_{\mathrm{L}} 1$ and $M_{\mathrm{L}} 4.9$. (Fig. 4). More detailed investigation of phase 2 shows two surges in activity, denoted here as phases $2 \mathrm{a}$ and $2 \mathrm{~b}$. Phase $2 \mathrm{a}$ occurred between 20 and 25 July, whereas phase $2 \mathrm{~b}$ began

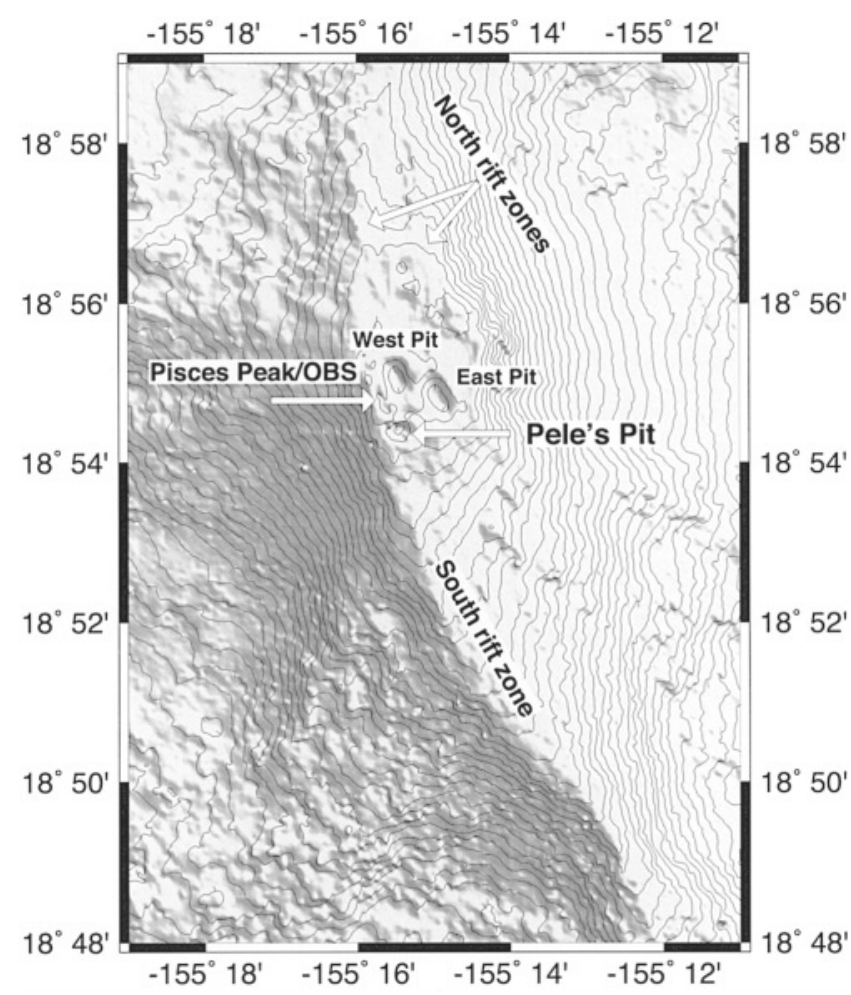

Figure 2. Bathymetry of Loihi seamount. Highlighted are the locations of Pele's Pit, the pit crater formed during the 1996 earthquake swarm, and Pisces Peak, the site where the OBS was deployed during the swarm. To the north and northeast of Pele's Pit are the two older pit craters, West Pit and East Pit. Contour interval is $100 \mathrm{~m}$. Illumination is from the northeast. Bathymetric data from the USNS Sumner, U. S. Naval Oceanographic Office.

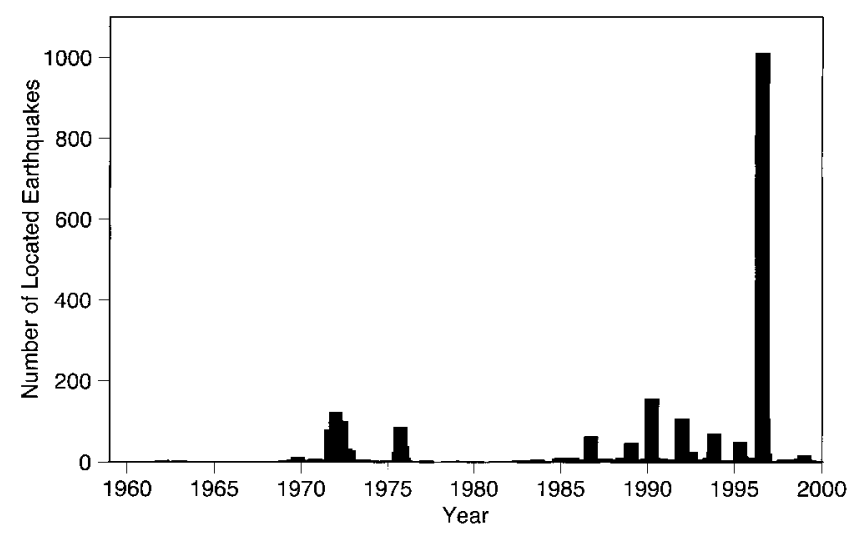

Figure 3. Monthly counts of earthquakes located at Loihi seamount. Background seismicity of $<10$ earthquakes per month is periodically interrupted by earthquake swarms, shown here in 1971-1972, 1976, 1986, 1989, 1990, 1991, 1993, 1995, and 1996. The 1996 swarm was the largest ever detected on Loihi. 


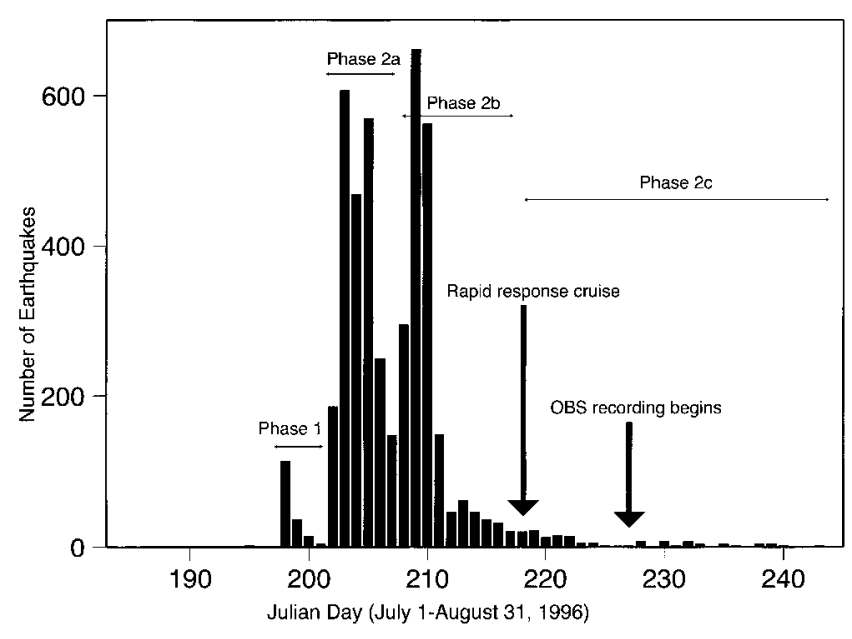

Figure 4. Daily counts of earthquakes in the 1996 Loihi seismic swarm. The swarm began on Julian day 198 (16 July) and tapered during the first three days of activity, denoted here as phase 1 . Phase 2 began on Julian day 202 (20 July) and continued until the swarm tapered throughout the month of August. Phase 2 consisted of two pulses of seismicity, denoted as phases $2 \mathrm{a}$ and $2 \mathrm{~b}$. Phase $2 \mathrm{c}$ represents all events that occurred after observations of the summit were made on the RRC. Also noted is the date when recording began on the OBS.

on 26 July and lasted through 5 August. During this time, over 4000 earthquakes were detected by the HVO network, 905 of which were located.

We define phase $2 \mathrm{c}$ of the swarm as beginning 6 August, coincident with the arrival of the first response cruise and the beginning of submersible and echosounder observations of the summit area. Based on these observations, we can constrain the formation of Pele's Pit and further deformation of the summit as occurring before phase $2 \mathrm{c}$. In contrast to the scattered epicenters of the phase 1 events, the phase 2 events cluster at the summit toward the south rift of the volcano (Fig. 5). The phase 1 events also have markedly higher peak frequencies than do the phase 2 earthquakes.

On 5 August a rapid response cruise (RRC) aboard the $\mathrm{R} / \mathrm{V}$ Ka imikai-o-Kanaloa sailed for Loihi to investigate the earthquake swarm and to seek evidence of an eruption. On the first traverse of the summit platform, the new Pele's Pit was imaged by the ship's echosounder. Because the phase 1 earthquakes were located beneath Loihi's southern flanks, researchers first looked for evidence of a south rift eruption, but no thermal or chemical anomalies were detected in that region (Duennebier et al., 1997). The presence of the new crater, as well as extensive faulting of the summit plateau, was confirmed on submersible dives on 7 August and 9 August (Duennebier et al., 1997). Glassy rocks, the freshest yet found on Loihi, were collected on Pisces Peak (Fig. 2). Radiometric dating of two of the rocks indicates that they erupted on Loihi in January and May of 1996, but the vent location for this eruption has not been identified (Garcia et al., 1998). Observations of fresh volcanic sands on Loihi's summit also suggest recent eruptive activity. Sonobuoys were used on a series of cruises following the earthquake swarm to locate explosive noises in the northeast region of Loihi's summit, but dives in that region were unsuccessful in locating an eruption site (Duennebier et al., 1997).

An ocean-bottom seismometer (OBS) was deployed on Pisces Peak (Fig. 2) on the 7 August dive. Because the OBS was deployed via submersible, it required no floatation and could be carefully placed in the lava talus, thereby limiting the amount of noise from deep ocean currents. The OBS contained a hydrophone and two $4.5-\mathrm{Hz}$ geophones that recorded motion in the vertical and horizontal directions. Due to a programming error, the OBS did not begin recording until 13 August whereupon it recorded continuous analog data until 28 August. The OBS was retrieved on 26 September.

\section{Processing of Seismic Data}

The seismic network operated by the Hawaii Volcano Observatory includes 53 short-period seismometers, 16 of which are three-component, distributed over the island of Hawaii (Fig. 1). The instruments are largely concentrated near the summit and rift zones of the active volcanoes $\mathrm{Ki}$ lauea and Mauna Loa. Data from the network are telemetered to the volcano observatory where they are timed using California Institute of Technology-U.S. Geological Survey Seismic Processing (CUSP) software and located with HYPOINVERSE (Klein, 1989).

In this study, we only include earthquakes that could be timed on a minimum of 10 seismic stations. The number of $P$ waves used in locating events averaged 26 , with a minimum of 10 and maximum of 52 picks. In general, $S$ waves are poorly defined and were picked on only a few stations.

During the swarm, initial timing was performed by a number of analysts at the Hawaii Volcano Observatory. After the swarm ended, one of the authors (J. Caplan-Auerbach) retimed all of the Loihi earthquakes to ensure consistency in the picking of $P$ and $S$ waves. Of the $\sim 4500$ quakes detected by the land-based HVO seismic network during the 1996 swarm, we were able to locate 1070 . Waveforms from events with overall rms travel-time residuals $>0.20 \mathrm{sec}$ were filtered with a 2-pole, 2-15 Hz butterworth bandpass filter to enhance the first breaks and retimed.

\section{Spectral Analysis}

Volcanic earthquakes are commonly divided into two categories according to source process. The first group, known as volcano tectonic (VT) earthquakes, are related to shear failure within the volcano (Lahr et al., 1994), are indistinguishable from other tectonic earthquakes, and are characterized by a broadband spectrum and clear $P$ and $S$ phases. The second group of volcanic earthquakes are the long-period (LP) events, characterized by a high-frequency onset and a long, harmonic coda. It is believed that many LP 


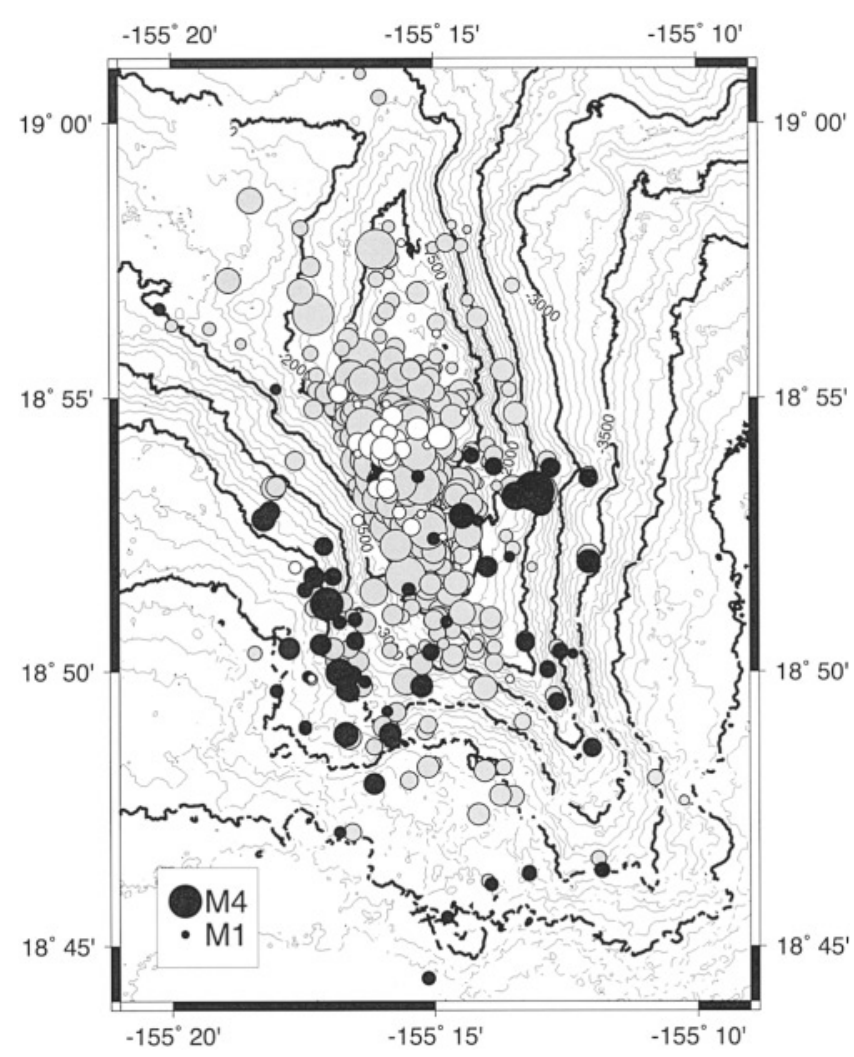

Figure 5. Events detected by $>10$ seismic stations, relocated with a combination of the Loihi-3 and Klein velocity models. Symbol size is proportional to local magnitude. Black circles represent phase 1 earthquakes, and gray circles represent phase 2 earthquakes (definitions of phase 1 and phase 2 earthquakes are given in the text and shown in Fig. 4). White circles represent earthquakes located using data from both the HVO network and the OBS and are the best constrained events. The earthquakes overlie Loihi bathymetry, contoured at $100 \mathrm{~m}$.

events represent volumetric deformation and are associated with fluid transport within the edifice (Chouet, 1988; Lahr et al., 1994; Chouet, 1996).

As shown in Figure 6, the phase 1 and phase 2 earthquakes have extremely different spectral characteristics. It is therefore useful to compare them to the VT and LP events observed on other volcanoes (Fehler and Chouet, 1982; Yamasato et al., 1991; Chouet et al., 1994; Pitt and Hill, 1994). Like VT events, many phase 1 earthquakes exhibit clear $P$ and $S$ phases and have spectral peaks near $8-10 \mathrm{~Hz}$ (Fig. 6). In contrast, the events of phase 2 resemble LP events, with spectral peaks near 2-4 Hz (Fig. 6), monochromatic codas, and poorly defined $S$ phases. Thus, at first glance it appears that the phase 2 events are associated with fluid transport and volumetric deformation.

Before we can categorize the Loihi earthquakes in this manner, however, we must consider the possibility that the spectral characteristics result from path and station effects rather than from the source. To this end, we analyzed aver- age daily power spectra for phase 1 and phase 2 events and compared the spectra at different seismic stations (Fig. 7). Spectra for a subset of earthquakes that are not associated with Loihi are also included in Figure 7. Because rays from these non-Loihi earthquakes follow different paths, spectra from these events may be used to differentiate between site and path effects.

Examination of the spectra in Figure 7 confirms that all of the seismic stations record higher frequencies for the phase 1 earthquakes. Phase 1 earthquakes show a wide variety of spectral peaks, while the phase 2 events appear to excite a narrow range of specific frequencies. Some peaks, such as the strong signal at $7.9 \mathrm{~Hz}$ on station PLAV and the $8.8 \mathrm{~Hz}$ peak on station DESV (Fig. 7), are independent of source location, ray path, and origin time, and are therefore considered to be site resonances.

Since the phase 1 and phase 2 earthquakes are concentrated in different parts of Loihi's edifice spectral differences could be either path or source effects. However, spectra from phase 1 and phase 2 earthquakes with similar epicenters still have extremely different spectral content, indicating that the spectral difference results from source processes rather than location. Depths, however, are poorly constrained for most Loihi earthquakes, and the possibility exists that a small difference in hypocentral depth may be sufficient to explain the spectral variation between phase 1 and phase 2 events.

On any given seismic station, nearly all of the phase 2 events display distinct spectral peaks, suggestive of source resonance. However, the frequencies of peaks differ from station to station, and therefore the resonances cannot be a source effect. Instead, we suggest that the phase 2 events have a broadband source signal, but the high frequencies are attenuated by the presence of a magma body within Loihi's edifice. Alternatively, the phase 2 events may have a broad, low-frequency spectrum indicative of low stress drops (Wyss, 1973).

Events detected at HVO's coastal stations show clear $T$ phases for most phase 2 events (Fig. 6), whereas $T$ phases are not evident for phase 1 earthquakes. However, $T$ phases from all phases of activity were detected on the Navy's SOSUS array by researchers at NOAA/PMEL (R. Dziak, personal comm., 1996). We suggest that the location of phase 1 earthquakes beneath Loihi's south flanks makes them poorly suited for the propagation of $T$ phases to the north, where they would be detected by the HVO stations.

\section{Ocean-Bottom Seismometer Data}

As a result of Loihi's position $30 \mathrm{~km}$ outside of the HVO seismic network, the locations of Loihi earthquakes are difficult to constrain, with the largest uncertainty in a vertical plane trending NNW-SSE. Hypocentral locations and additional swarm characteristics are dramatically improved by data from the OBS. Additionally, the deployment of an OBS on Loihi allow us to use rays that have passed through the volcano to analyze Loihi's velocity structure. 

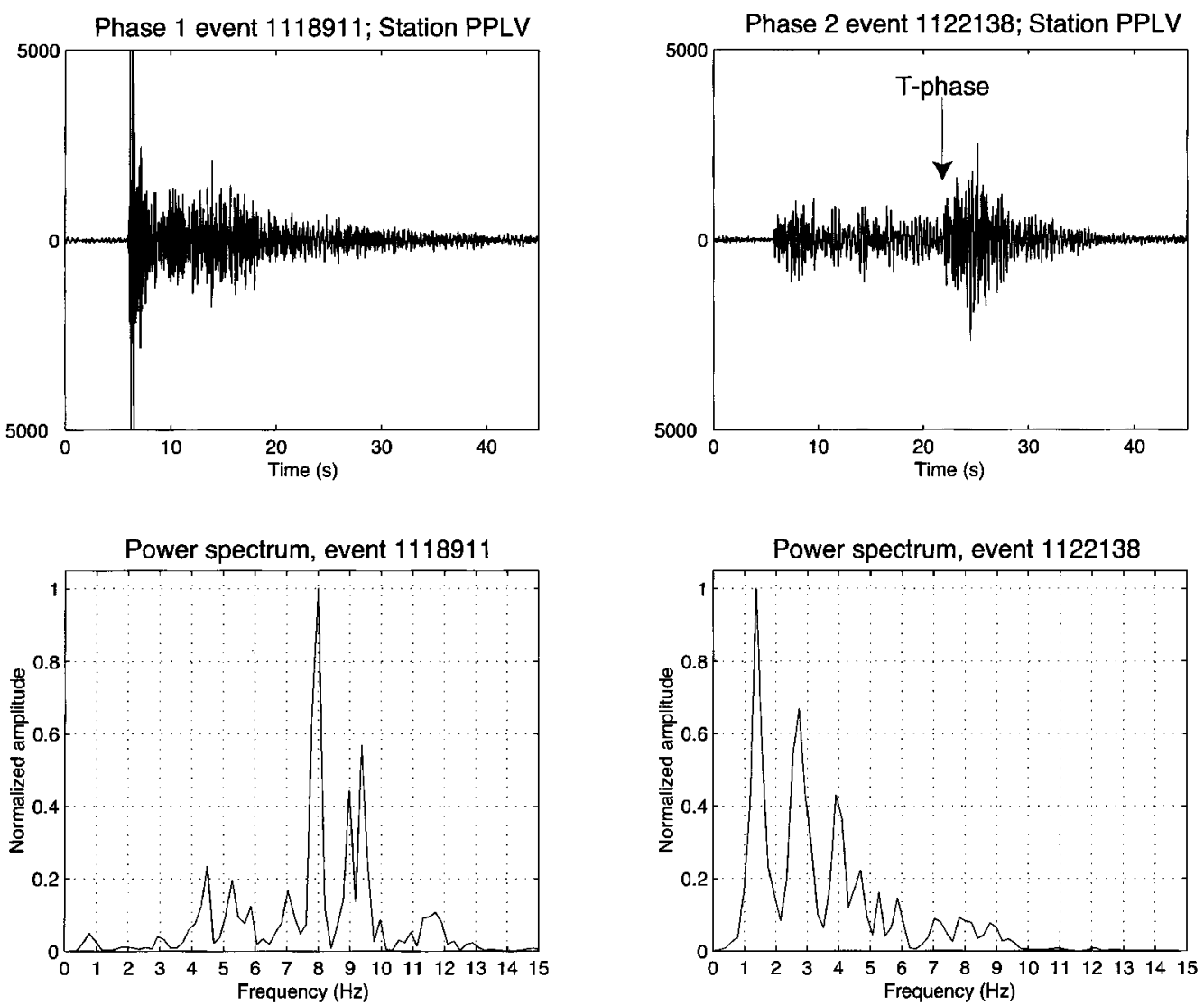

Figure 6. Waveforms and power spectra for typical phase 1 and phase 2 earthquakes. Both earthquakes have magnitude $M_{\mathrm{L}} 2.6$ and both are from the PPLV station of the HVO seismic network (Fig. 1). (a) Phase 1 event from 16 July 1996. The peak energy is carried in the $P$ wave, with little coda. Spectral peaks are at $8-9 \mathrm{~Hz}$. (b) Phase 2 event from 28 July 1996 with spectral peaks at 1.4, 2.7, and $3.9 \mathrm{~Hz}$. Also visible is a $T$ phase at $\sim 20 \mathrm{sec}$. The power spectra were calculated with a 512-point fast Fourier transform on the first $10 \mathrm{sec}$ of the waveforms to avoid interference from the $T$ phase.

During the time that the OBS was operational, 42 earthquakes were detected by both the OBS and HVO's land-based network. Approximately 450 additional events were detected on the OBS that were not sufficiently large to trigger the land-based network, and many events were within the coda of earlier earthquakes. As a result, of the 42 events detected by both the HVO network and the OBS, only 36 could be reliably located. Waveforms from the HVO network for the OBS-detected events were filtered and retimed.

To evaluate the importance of the OBS, we first located the 36 OBS-detected events using arrivals from the HVO stations only, with Klein's (1981) velocity model (the model used by HVO for location of Hawaii island earthquakes). Travel-time residuals for these initial locations averaged $0.18 \mathrm{sec}$. However, when the OBS data are included in the solution calculations, the OBS $P$ waves are found to arrive up to $1 \mathrm{sec}$ early and the overall rms residual for the events jumps to $0.57 \mathrm{sec}$. Because of our high confidence in the OBS picks $(<0.10 \mathrm{sec})$, we attributed the high residuals to an inaccurate velocity model at Loihi rather than to timing errors. Without data from the OBS, the inappropriateness of the Klein velocity model for Loihi would not have been evident, thus emphasizing the importance of having a seismic station on Loihi.

\section{A New Velocity Model}

We considered two models as possible explanations for the early arrivals on the OBS: fast, shallow seismic velocities relative to the Klein model or lower velocities at depth between Loihi and Hawaii island. To evaluate the first of these possibilities, we used the Klein velocity model and fixed the location of the 36 OBS-recorded earthquakes at 7-km depth, directly beneath Loihi's summit. The results of this calculation suggested that if the Klein velocity model is retained at depths $>7 \mathrm{~km}$, the velocity of the shallowest $7 \mathrm{~km}$ would have to exceed that of the mantle in order to explain the OBS residuals. Fixing the earthquakes at depths shallower than $7 \mathrm{~km}$ requires even higher velocities. We therefore concluded that the high residuals on the OBS cannot be ex- 

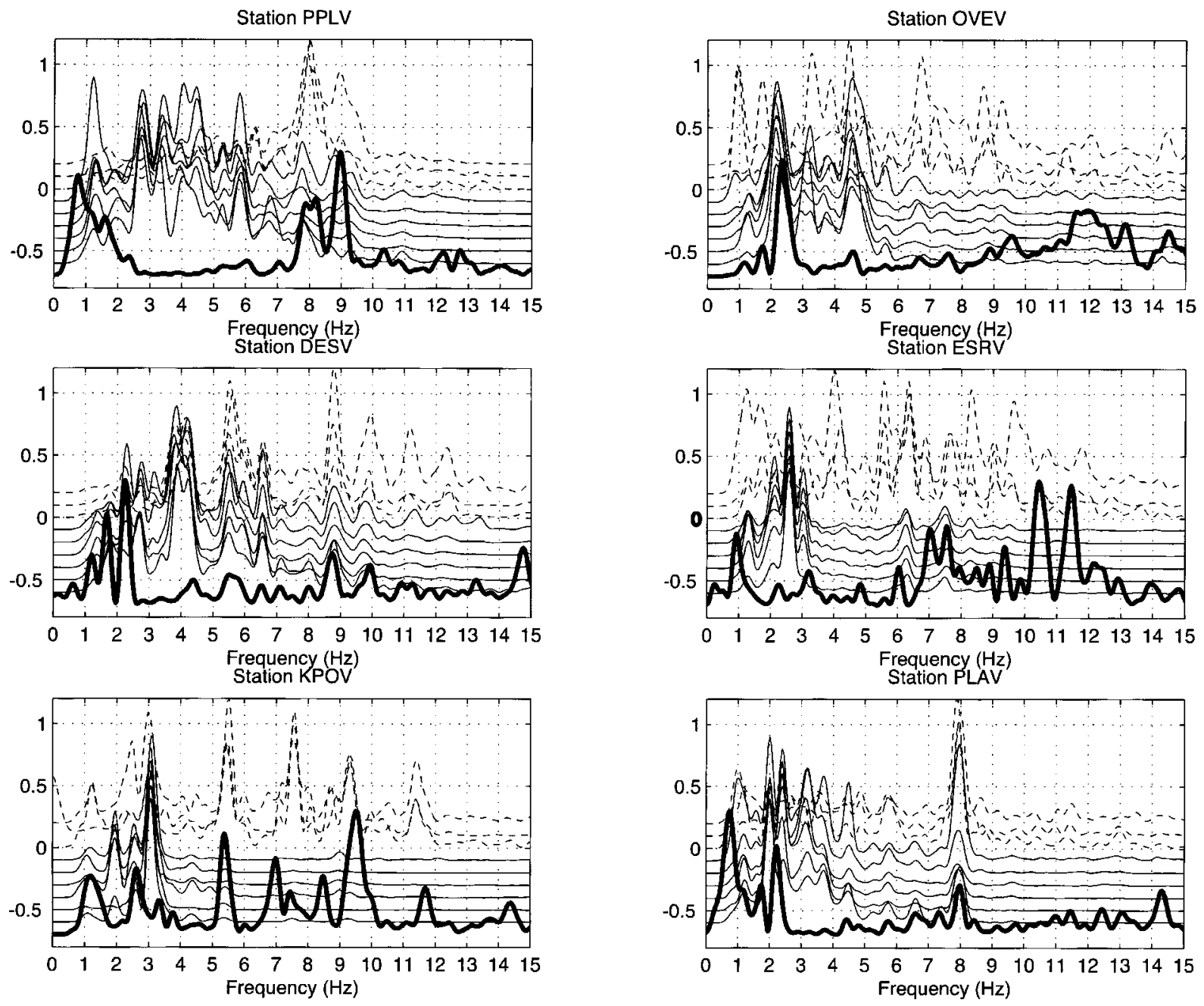

Figure 7. Averaged daily power spectra for different categories of earthquakes. Dashed lines represent phase 1 power spectra, thin solid lines represent phase 2 spectra and the heavy solid lines represents spectra for a group of non-Loihi earthquakes. All stations show higher peak frequencies for the phase 1 events and lower peak frequencies for phase 2 earthquakes. Several spectral peaks are seen for all classes of earthquakes and are thought to be site effects. While the phase 2 events have lower peak frequencies, the spectra differ between stations, suggesting that the spectral peaks are not indicative of source resonance.

plained solely by faster, shallow velocities and that an appropriate velocity model for Loihi must include lower velocities at depths below the hypocenters.

To estimate the appropriate velocity structure, we began with the Klein velocity model and iteratively increased or decreased layer velocities to minimize the travel-time residuals. Our first priority was to minimize the residuals at the OBS and then to minimize the overall $\mathrm{rms}$ residuals for all stations. Additional constraints on the velocity model came from the refraction work of Kong et al. (1997) and Hill and Zucca (1987). Because it has been shown to be effective in locating Big Island earthquakes, we retained the Klein velocity model for the Big Island of Hawaii, changing only the offshore velocities in the area shown by the circle around Loihi in Figure 1.
Because we only had a single receiver on Loihi, we were unable to determine a unique velocity model for Loihi earthquakes. Two examples of models with low rms travel-time residuals, called Loihi-3 and Loihi-4, are shown in Figure 8 with Klein's (1981) linear gradient velocity model displayed for comparison. Because Loihi's summit is still $\sim 1000 \mathrm{mbsl}$, we included seawater velocities in the shallowest kilometer of the Loihi models shown in Figure 8. However, it should be noted that HYPOINVERSE does not consider station elevation, and depths are defined relative to the stations. Thus, when used for earthquake location, the Loihi velocity models do not include the water column, and topography is incorporated into the station corrections.

The station delays used by HVO in locating Big Island earthquakes were calculated for rays traveling within 


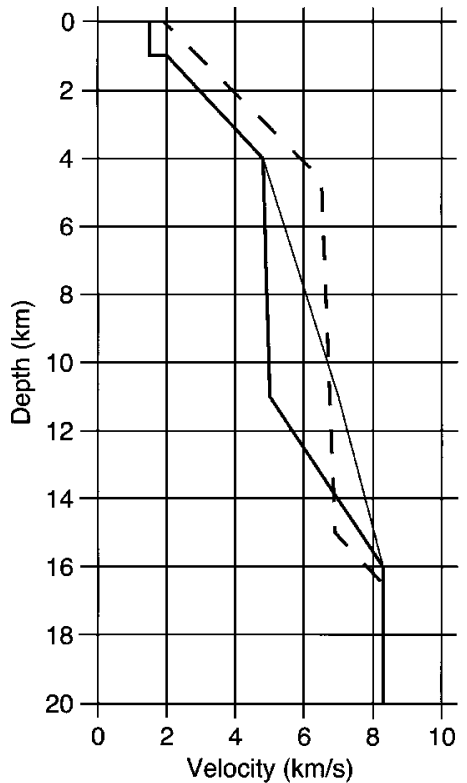

Figure 8. Loihi-3, Loihi-4, and Klein compressional velocity models (heavy solid, thin solid, and dashed lines, respectively). The shallowest kilometer shown here represents the water column above Loihi's summit and is not used in calculations.

Kilauea and may therefore be inappropriate for Loihi sources. During the retiming of the swarm, a subset of large $\left(>M_{\mathrm{L}} 3\right)$, high signal-to-noise ratio events was selected for use in estimating new station corrections. Unfortunately, none of the OBS-detected events had sufficiently clear $P$ wave arrivals to include in the calculation of station delays. After relocating these events, travel-time residuals were calculated and, where a clear trend was evident, the station delays were corrected accordingly. Because the OBS sat at $\sim 980 \mathrm{mbsl}$, we assigned it a station delay of $-0.35 \mathrm{sec}$, the calculated travel time for a $\mathrm{P}$ wave in the first $980 \mathrm{~m}$ of the Loihi-3 velocity model. However, because HYPOINVERSE operates by minimizing residuals at the nearest station, changing the station correction for the OBS has little effect on earthquake hypocenters.

While both of the Loihi models displayed in Figure 8 yield low rms residuals, we do not have sufficient data to discriminate between them. We used both Loihi-3 and Loihi4 to calculate hypocenters for the 36 OBS-detected events and found that increasing the mid-depth (4-14 km) velocities shallows earthquake hypocenters and moves them to the south. While we cannot establish which model is more accurate, the Loihi-3 model is appealing because it yields the lowest rms residuals. Moreover, hypocenters calculated with Loihi-3 fall directly beneath Pele's Pit, a region in which we expect seismic activity. We therefore use the Loihi-3 model for earthquake relocations in this article. While hypocenters calculated for the OBS-detected events are quite sensitive to changes in the velocity model, other events are relatively unaffected by variations in the Loihi model. Consequently, choosing Loihi-3 over Loihi-4 as the optimum model has little effect on our interpretation of the swarm.

Below the water column, the shallowest three kilometers of the Loihi-3 model have $P$-wave velocities increasing from 2.0 to $4.8 \mathrm{~km} / \mathrm{sec}$ (Fig. 9 and Table 1), comparable to Kilauea rock velocities. Because rays that passed through Loihi's shallowest region were only detected at the OBS, velocities in this layer are relatively poorly constrained. To further evaluate shallow velocities, we considered preliminary data from a seismic refraction study recently performed over Loihi (Caplan-Auerbach et al., 1998). These data suggested that the shallowest 100-200 m of the volcano have velocities near $2.0 \mathrm{~km} / \mathrm{sec}$. Between depths of 4 and $11 \mathrm{~km}$, the Loihi-3 model indicated a low-velocity gradient with velocities hovering near $5 \mathrm{~km} / \mathrm{sec}$. At 11-km depth, the velocity increased again and reached mantle velocities at $16 \mathrm{~km}$.

One possible explanation for low mid-depth velocities stems from the fact that Loihi formed on the flanks of Mauna Loa and Kilauea and is likely underlain by hyaloclastites and landslide debris from the Big Island. These layers of debris should be slower than material at comparable depths beneath Kilauea. Moreover, refraction studies indicate that the weight of Hawaii island causes the underlying crust and lithosphere to flex downward, resulting in velocity layers that dip in a landward direction (Hill and Zucca, 1987). We recognized that velocities in the Loihi-3 model likely reflected the passage of rays through a dipping layer and may not have been indicative of actual rock velocities beneath the volcano. To further examine the case for a dipping layer model, we performed ray tracing between Loihi and Hawaii island for a dipping layer structure and for the combination of the Klein and Loihi-3 velocity models. The results of this ray tracing showed no significant difference in travel times. The low velocities in Loihi-3 may therefore have represented the part of the raypath that travels through the low-velocity dipping layer rather than the compressional velocity of the rock.

Because this study used only a single receiver on Loihi, we were unable to investigate heterogeneities within the volcano. It is likely that velocities differ significantly between Loihi's rift zones and flanks. Such heterogeneities were detected by a 1986 Loihi OBS survey (Bryan and Cooper, 1995) and have been imaged in a preliminary refraction study of Loihi (Caplan-Auerbach et al., 1998). In order to produce a more complete model for Loihi, a network of seismic stations would be needed on the seamount.

\section{Earthquake Relocation}

To evaluate the effects of the new velocity model on earthquake locations, we present the initial and relocated hypocenters for the 36 earthquakes detected by the OBS and the HVO network (Fig. 9). The initial locations shown in Figure 9a were calculated using Klein's (1981) velocity model and the original station delays. Figure $9 \mathrm{~b}$ shows the same events relocated using the new station delays as well 
(a)

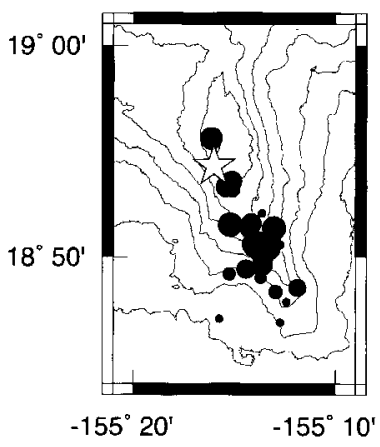

(c)

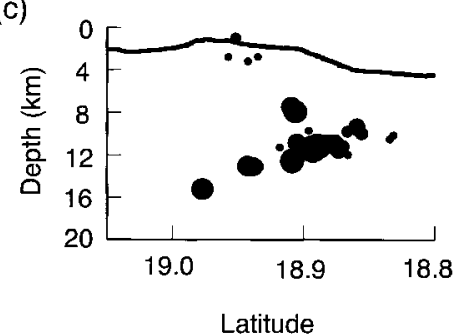

(e)

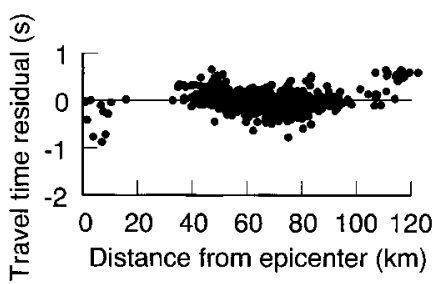

(b)

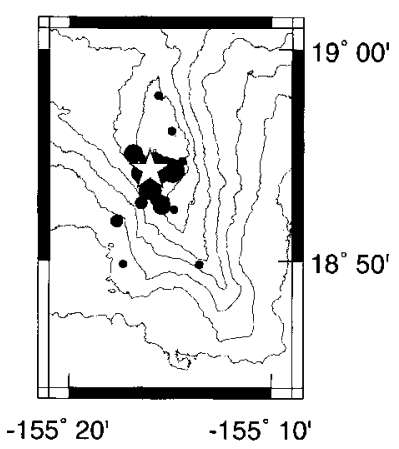

(d)

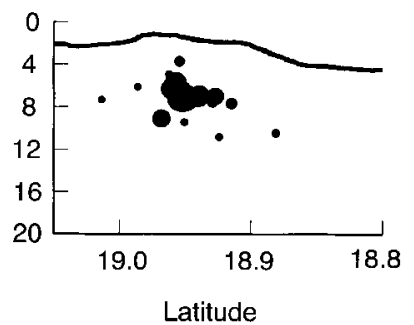

(f)

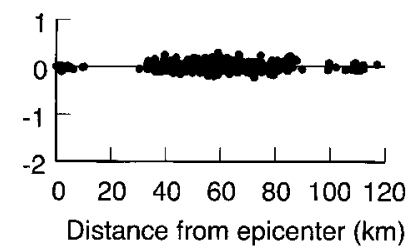

Figure 9. Original and relocated epicenters for the 36 events detected by the OBS and by the land-based seismic network. For all figures, original locations are made using original station delays and Klein's (1981) velocity model only. For the relocation we used new station delays and a combination of the Loihi-3 velocity model with Klein's (1981) model. The Klein model is used for the Big Island of Hawaii, with Loihi-3 in the offshore region. (a) Original epicentral locations: the location of Pele's Pit is marked by a star; (b) relocated epicenters; (c) original hypocentral depths; (d) relocated depths; (e) original rms travel-time residuals for the events plotted above; (f) rms travel-time residuals for the relocated events.
Table 1

Loihi Velocity Models

\begin{tabular}{ccc}
\hline & Loihi-3 & $\begin{array}{c}\text { Loihi-4 } \\
\text { Depth }(\mathrm{km})\end{array}$ \\
\hline 0.0 & $P$-Wave Velocity $(\mathrm{km} / \mathrm{sec})$ & $P$-Wave Velocity $(\mathrm{km} / \mathrm{sec})$ \\
1.0 & 1.5 & 1.5 \\
4.0 & 2.0 & 2.0 \\
11.0 & 4.8 & 4.8 \\
16.0 & 5.0 & 7.0 \\
\hline
\end{tabular}

Depths are relative to sea level. In all layers except the water column (the first $\mathrm{km}$ ), velocities increase according to a linear gradient. The deepest layer is a half-space with velocity $8.3 \mathrm{~km} / \mathrm{sec}$.

as the combination of the Klein and Loihi-3 velocity models. The relocated earthquakes cluster more closely under the summit and are centered near the new pit crater, indicated by a white star. The rms travel-time residual for the OBSdetected events located with Loihi-3 is 0.07 sec (Fig. 9f).

Relocated epicenters are plotted in Figure 5 for all events in the 1996 swarm that were detected by 10 or more stations. The black circles in Figure 5 represent epicentral locations of the phase 1 events, and phase 2 earthquakes are shown in gray. The best constrained events are those detected by both the HVO network and the OBS and are represented by the white circles. Circle size is proportional to local magnitude as calculated by HYPOINVERSE (Klein, 1989).

\section{Hypocentral Depths}

Hypocentral depths calculated for the OBS-detected earthquakes are included in Figure 9. Initial depths calculated with the Klein velocity model and the original station delays fall along a line between 10 and $14 \mathrm{~km}$ depth, shallowing to the south (Fig. 9c). The relocated hypocenters shown in Figure 9d, however, form a tight cluster at a depth of $\sim 6-7 \mathrm{~km}$ beneath Loihi's summit. Use of the Loihi-4 model shallows the hypocenters to depths of $2-5 \mathrm{~km}$ beneath the summit, but also moves them to the south, away from the pit crater. Regardless of the velocity model used, the OBS-detected events form a tight cluster with a diameter only slightly greater than their individual error ellipses. Thus, we conclude that although the absolute depth is not known with certainty, the clustering implies a marked improvement in the relative locations of these events.

To investigate the robustness of our depth calculations, we computed travel-time residuals for the 36 OBS events for a range of fixed depths $(1-15 \mathrm{~km})$, the results of which are displayed in Figure 10. We first performed the calculations using only the Klein velocity model, and then again using 
combinations of the Klein model with the Loihi-3 and Loihi4 models. As shown in Figure 10, residuals are considerably lower for the events located with Loihi-3 and Loihi-4, and the residual curves for those models are steeper, indicating better depth constraint. Finally, we ran the same test using the Loihi-3 velocity model, disregarding data from the OBS (Fig. 10). In this case, although the rms residuals are extremely low, the curve is nearly flat for all depths $>3 \mathrm{~km}$, confirming that without arrivals at Loihi, we have virtually no constraint on hypocentral depth.

A common result of all of the depth calculations is that the OBS-detected events appear to have a source region $>3 \mathrm{~km}$ beneath Loihi's summit. That the earthquake depths do not appear to be shallow is at first surprising, given the spectacular deformation observed on Loihi's summit. However, a similar pattern of summit deformation and deep seismicity was observed in the 1968 caldera collapse of Fernandina volcano in the Galapagos islands (Simkin and Howard, 1970), suggesting that this pattern is not unique to Loihi. Despite the obvious effects of faulting on the volcano's summit topography, teleseismic waveform modeling suggests that the source of the Fernandina quakes was a fault located at 14-km depth (Kaufman and Burdick, 1980). Similarly, Hirn et al. (1991) noted that the source depth for long-period seismicity associated with the collapse of a pit crater on Piton de la Fournaise volcano, while difficult to constrain, appears to be deeper than the plug forming the pit crater bottom. Such parallels on other volcanoes suggest that deep faulting at Loihi is not inconsistent with the shallow deformation.

\section{Swarm $b$-Value}

Most volcanic earthquake swarms are composed of many small $(<M 3)$ earthquakes. The rarity of large earthquakes in such episodes means that for volcanic earthquake swarms, the $b$-value, the slope of the frequency-magnitude relation $\log N=a-b M$, is high, often exceeding 2 (McNutt, 1986). The 1996 Loihi earthquake swarm, however, included over 100 quakes with magnitude $>M_{\mathrm{L}} 4$, making the $b$-value of the swarm of particular interest. A slight dropoff in the number of events with magnitude $<M_{\mathrm{L}} 1.5 \mathrm{sug}$ gests that this is the approximate completeness threshold for Loihi events detected at the HVO stations. If we assume that the earthquake catalog is complete for events of magnitude $>M_{\mathrm{L}} 1.5$, we find that the magnitude-frequency plot is best described by two $b$-values (Fig. 11). Events with magnitudes $<M_{\mathrm{L}} 4.5$ have a $b$-value of 0.42 , while events with magnitudes $>M_{\mathrm{L}} 4.5$ have a much higher $b$-value of 2.42. Further analysis of the $b$-value for the swarm shows that the phase 1 earthquakes have a slightly higher $b$-value than the events of phase 2. Phase 1 earthquakes have a $b$-value of 0.63 .

The $b$-values calculated for the Loihi swarm were similar to those found by Filson et al. (1973), who showed the same bimodal relationship for earthquakes associated with the caldera collapse at Fernandina volcano in 1968. Because

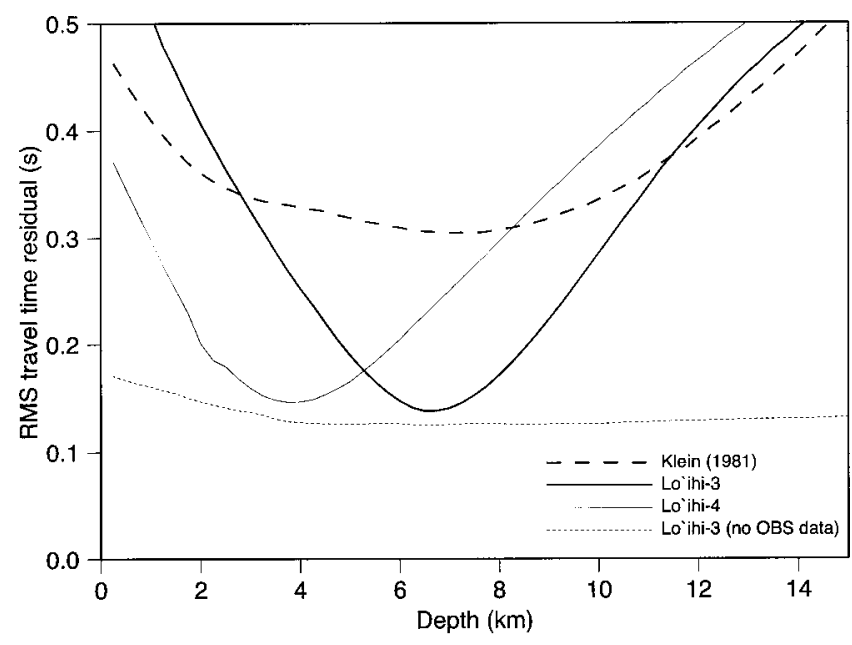

Figure 10. The rms travel-time residuals calculated for the 36 OBS-detected earthquakes with fixed depths. Residuals for events located using only the Klein velocity model are represented by the thick dashed line. The rms residuals for the Loihi-3 and Loihi-4 models are shown in thick and thin solid lines, respectively. The thin dashed line shows residuals for events located with the Loihi-3 model, but without data from the OBS, confirming that a station on Loihi is required to constrain depth.

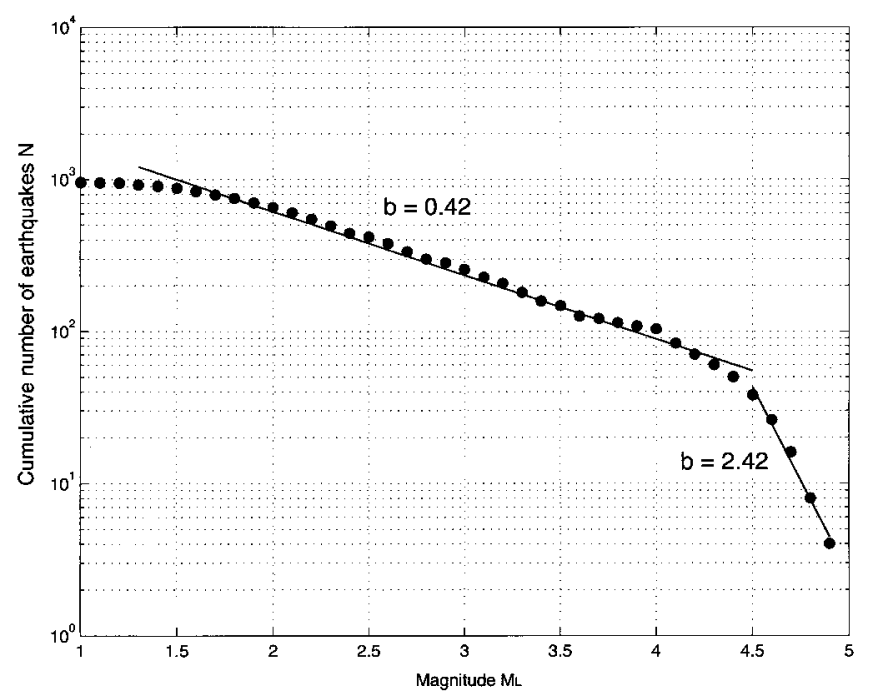

Figure 11. Magnitude-frequency plot for the 1996 Loihi earthquake swarm. Magnitudes are local magnitudes as calculated using HYPOINVERSE (Klein, 1989). $N$ is the cumulative number of events with magnitudes $>M_{\mathrm{L}}$. Data are only considered complete for events of $M_{\mathrm{L}}>1.5$. The data are best fit by two $b$-value lines, one for events with $M_{\mathrm{L}}<4.5$ (b = $0.42)$ and one for $M_{\mathrm{L}}>4.5(b=2.42)$. 
Wyss (1973) suggested that $b$-value is inversely related to stress drop, Francis (1974) attributed the dual $b$-values at Fernandina to the occurrence of two types of earthquakes: the events with the higher $b$-values are thought to be low stress drop quakes associated with the main caldera ring fault while the smaller events are thought to have high stress drops and locate on minor faults distributed throughout the volcanic edifice. An alternative model for the $b$-values is found in the work of Ben-Zion and Rice (1995) who showed that a bimodal $b$-value may result from strong heterogeneities along a fault. The fact that the $b$-values are different for the phase 1 and phase 2 events likely reflects differences in fault properties on Loihi's summit and flanks.

\section{Faulting and Focal Mechanisms}

We can also use earthquake focal mechanisms to evaluate the relationship between the earthquake swarm and the formation of the pit crater. Unfortunately, many of the phase 2 earthquakes have emergent arrivals, making first motions difficult to characterize. We selected a subset of large earthquakes that were noted as having at least 40 clear $P$-wave motions, or $33 P$-wave motions if one was from the OBS. While phase 1 earthquakes seem to display a variety of first motions, virtually all of the $P$-wave arrivals for phase 2 earthquakes are dilatational.

The limited range of takeoff angles for Loihi earthquakes detected at HVO stations makes fault plane solutions impossible to constrain (Fig. 12). We can, however, use these data to rule out thrust or pure strike-slip faulting for the phase 2 events. Although the calculated focal mechanisms indicate normal faulting, they are also consistent with a non-double-couple source mechanism such as that generated by ring fault earthquakes (Julian, 1998). Ring faulting is appealing due to the formation of Pele's Pit, but the data are insufficient to form conclusions about the nature of the faulting. The diversity of first motions among phase 1 earthquakes indicates a greater variety of focal mechanisms in the early part of the swarm.

The calculated focal mechanisms are strongly dependent on hypocentral depth, the least well constrained factor in our earthquake locations. To examine the robustness of our solutions, we recalculated focal mechanisms for fixed earthquake depths between 2 and $15 \mathrm{~km}$ and found that in general, the phase 2 focal mechanisms were consistent with normal faulting for all depths shallower than $14 \mathrm{~km}$.

We can further evaluate faulting at Pele's Pit by investigating magnitudes of earthquakes generated by the downdropping pit. Although the dimensions of the fault are uncertain, we assumed that the floor of the pit crater drops as a coherent plug and that the size of the fault is the same as the surface area of the dropping cylinder. Because none of the earthquakes are larger than $M_{\mathrm{L}} 4.9$, we can assume that the local magnitude is approximately equal to the moment magnitude and estimate the fault dimensions accordingly. We estimated the thickness of the plug to be $3 \mathrm{~km}$, assuming that it sits over a shallow magma chamber, like that assumed for Kilauea (Tilling and Dvorak, 1993). A M 4.9 earthquake on this fault would result in $0.13 \mathrm{~m}$ of fault displacement, requiring many hundreds of earthquakes $>M 4$ to yield the observed 300-m pit crater depth. The fact that the crater appears to have formed with a series of small displacements is consistent with observations of precarious rocks on the crater wall and lack of ejecta on the crater rim, as well as with the large number of earthquakes in the swarm. These fault dimensions also allowed us to rule out the possibility that the pit crater formed in a single catastrophic event. Even if we assumed that the crater floor has a thickness of only a few hundred meters, a single collapse event would yield an earthquake of $M 6.5$, far larger than any observed during the swarm.

\section{Discussion}

Many models exist for the formation of pit craters. While some authors suggest that a pit crater drops as a single pistonlike block (Filson et al., 1973; Francis, 1974; Hirn et al., 1991), others (Walker, 1988; Okubo and Martel, 1998) suggest that pit craters form when stoping occurs over large, opening-mode fractures. A third model (Gudmundsson, 1998) suggests that a crater ring fault may develop over a small magma body if a wide portion of the volcano undergoes upward doming. Although we have used the piston model in our discussion of earthquake magnitudes, we are unable to rule out the possibility that the crater formed through stoping. The doming model is appealing in that it could explain the broad distribution of earthquake prior to phase 2, but no data are available to determine whether or not doming occurred on Loihi.

Although the method of collapse is different in each of the models, all require that rock from the pit crater either falls or subsides into an underlying chamber. In the case of Loihi, this implies that some magmatic event, eruption or intrusion, occurred to remove magma from a summit magma chamber. Here, we investigated the 1996 swarm for evidence of an eruption or intrusion and to determine the chain of events leading up to the formation of the pit crater.

Any model seeking to explain the events of 1996 on Loihi seamount must account for the following observations already discussed in this article: (1) there was intense seismicity for nearly a month, with over 100 events larger than magnitude $M_{\mathrm{L}} 4$; (2) the earthquake swarm included several pulses of activity, with the high-frequency phase 1 events occurring beneath the south rift zone, while the lowfrequency phase 2 events clustered beneath Loihi's summit; (3) radiometric dating of samples collected at Loihi's summit confirmed that Loihi erupted in early 1996 when the volcano was seismically quiet (other data, including water chemistry and sonobuoy signals suggested that an eruption was in progress during the swarm); (4) the best constrained hypocentral depths appeared to cluster several kilometers beneath Loihi's summit; (5) limited focal mechanism data 


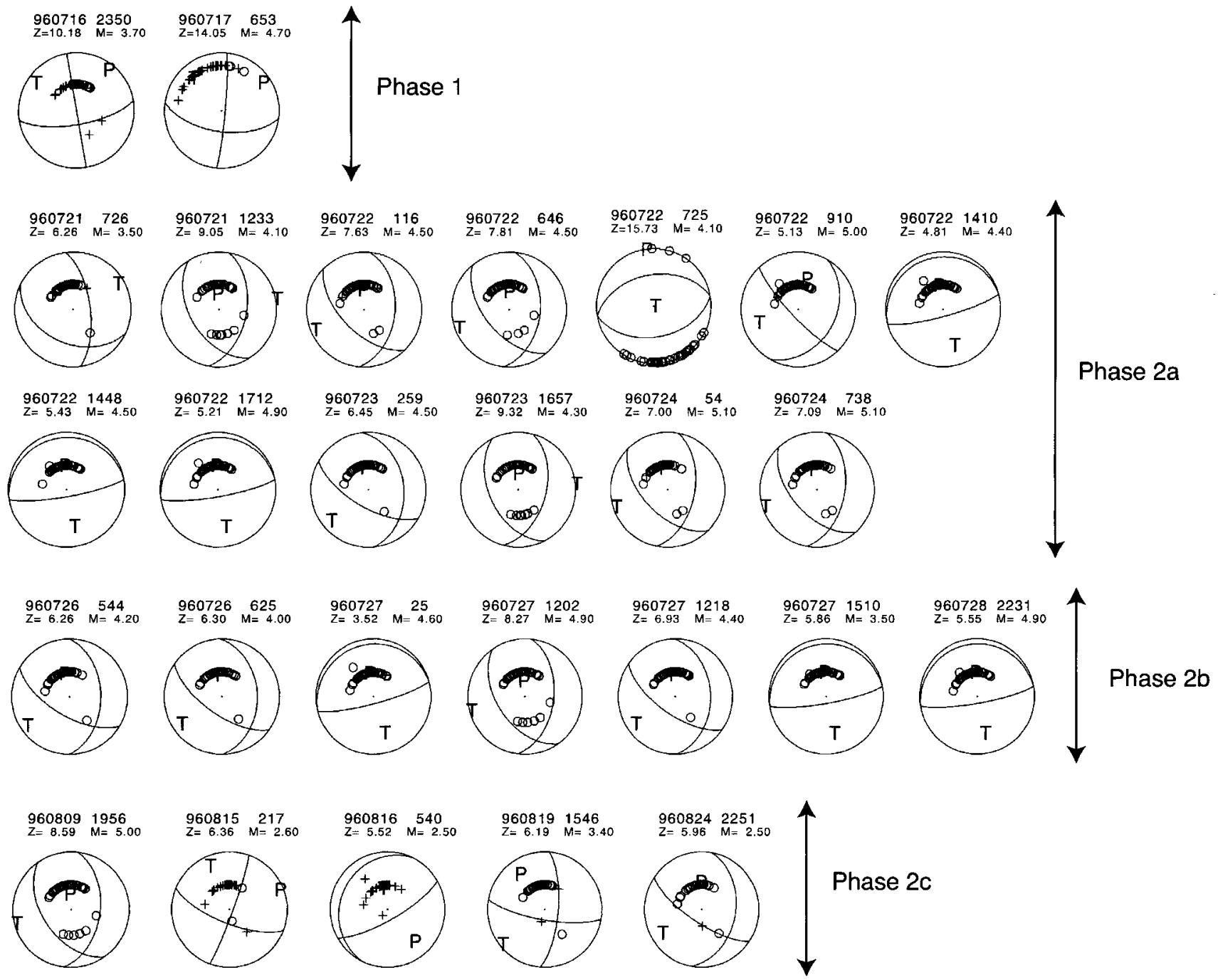

Figure 12. Focal mechanisms for a subset of swarm events, calculated using FPFIT (Reasenberg and Oppenheimer, 1985). The majority of phase 2 events have focal mechanisms consistent with normal or ring faulting. Virtually all first motions for phase $2 \mathrm{a}$ and $2 \mathrm{~b}$ events are dilatational. Phase 1 and phase $2 \mathrm{c}$ earthquakes show a variety of first motions.

indicated normal or ring faulting for the phase $2 a$ and $2 b$ events, with a greater variety of faulting types in phases 1 and 2c; and (6) submersible observations of Pele's Pit, as well as earthquake magnitudes, suggested that the pit collapsed gradually rather than in a single catastrophic event.

In both the 1986 pit crater formation at Piton de la Fournaise and the 1968 caldera collapse at Fernandina volcano, crater collapse occurred at the end of a long, complex eruptive cycle (Hirn et al., 1991). Although radiometric dating confirms that Loihi erupted in January-February and May 1996 (Garcia et al., 1998), it is not known whether these dates represent two distinct eruptive events or a single, prolonged eruption. The relative lack of seismicity during early 1996 is reminiscent of the low seismicity associated with the current, long-term, eruption of Kilauea volcano (Koyanagi et al., 1988). Although Kilauea experiences periodic earth- quake swarms, transport of magma to the east rift zone vent site is largely aseismic, suggesting that magma flows uninhibited through pre-existing conduits. The eruption that took place on Loihi in early 1996 must have been similarly quiescent, with magma moving freely from an overflowing reservoir to the vents. During this time, drainage of the magma chamber due to erupted lava must have been rapidly replenished. The draining of the magma chamber that resulted in pit crater formation was likely a consequence of adjustments causing the initial part of the swarm rather than the volcano's long-term behavior.

It is not known where the magma went upon draining from the magma chamber, but there are at least three possibilities: the magma may have erupted, it may have intruded along one of the rift zones, or it may have drained into a deeper reservoir. Although evidence exists that Loihi was 
erupting at the time of the RRC, no eruption site has been found, suggesting either that the eruption was small or that it occurred in a region not visited by the submersible. Data from water samples suggested that a deep eruption occurred on Loihi during the swarm, but that eruption is also thought to have been short-lived (Duennebier et al., 1997). Although the phase 1 events occurred in the southern part of Loihi, their scattered epicentral distribution does not support a dike intrusion. Seismicity associated with dike intrusions on $\mathrm{Ki}$ lauea volcano is generally tightly clustered and may migrate down the rift zone (Klein et al., 1987), characteristics not seen in the phase 1 events.

Petrologic evidence from rocks collected during the earthquake swarm shows partial crystallization in a deep (8$10 \mathrm{~km}$ ) magma chamber, just below the best-fit depths for the earthquakes recorded by the OBS (Garcia et al., 1998). The possibility exists that a shallow magma chamber drained into a deeper reservoir during phase 2 of the swarm, resulting in the formation of Pele's Pit. The relatively low frequency of the phase 2 events is consistent with the presence of magma within the volcano and may indicate faulting near a magmatic conduit. The lack of clearly defined $S$ waves for phase 2 earthquakes also suggests that seismic energy may have passed through a magma chamber or conduit en route to the HVO stations.

We suggest that the phase 1 faulting triggered drainage of the magma chamber, thereby instigating the phase 2 activity as well. Phase 1 events are generally of higher frequency and shorter duration than the phase 2 events, suggesting that they are associated with brittle rock fracture. A possible model is that the cumulative pressure increase due to repeated magma injection within Loihi and gravitational loading of the edifice resulted in the buildup of strain within the southwest flank. During phase 1, rupture within the flank opened passages into which magma could drain. Instead of a single slip event, we envision a cascade of smaller earthquakes that created fractures within Loihi's south flanks. Magma may then have drained from either the deep or shallow magma chambers beneath Loihi.

Once magma began to withdraw from the summit reservoir, the slow collapse of Pele's Pit ensued, yielding a large number of concentrated earthquakes in phase 2. Not only are the phase 2 events clustered beneath Loihi's summit, but their focal mechanisms also suggest faulting consistent with the downdropped pit crater. We were unable to resolve any clear difference between the events of Phase $2 \mathrm{a}$ and $2 b$, but recognized them as distinct units in time. One of the phases may be associated with the pit crater, while the other represents additional deformation of the summit platform, but the phase 2 epicenters are not sufficiently well constrained to confirm this model. Phase $2 \mathrm{c}$ represents the tapering phase. The major faulting of the summit occurred before 7 August, when the first submersible observations were made. At this stage, most seismicity was probably associated with settling of the edifice and movement of magma.

\section{Conclusions}

The 1996 earthquake swarm was the largest yet detected on Loihi and among the largest ever observed on a Hawaiian volcano. The swarm consisted of two major phases distinguished by time, location, and spectral content. The seismic activity was associated with the formation of a new pit crater and with significant deformation of the summit platform.

The deployment of an OBS during the swarm enabled us to construct a new velocity model for the Loihi region. Early arrivals on the OBS suggest that the Klein's (1981) model used for Hawaii island is too fast for Loihi earthquakes. Relocation of swarm events using a combination of the Klein velocity model and the new Loihi-3 model showed that the phase 2 events clustered near Loihi's summit. While depths are highly sensitive to the velocity model, the Loihi3 model indicated depths of $\sim 6-7 \mathrm{~km}$ beneath Loihi's summit, just above the deep magma body inferred from petrologic data.

The new velocity model for Loihi and determination of hypocentral depths for the swarm events could only be achieved with data from the OBS. In order to fully investigate the seismicity and internal structure of Loihi seamount, it was important that instrumentation was deployed on the volcano itself and in the surrounding area.

We offer the following model for the events that led up to the 1996 Loihi seismic swarm. During a period of many years, a summit magma chamber on Loihi filled. Presumably, some of the earthquake swarms detected on Loihi between 1971 and 1995 resulted from eruptions or dike intrusions from this magma chamber. In early 1996, according to the model of Garcia et al. (1998), magma from a deep $(8-10 \mathrm{~km})$ reservoir intruded into the shallow chamber, triggering an eruption. The lack of seismicity during this time suggested that the magma may have reoccupied hot passageways within the edifice and that the shallow chamber remained full, recharged from a deeper source. On 16 July 1996, brittle rupture occurred within Loihi's southwest flank, resulting in the opening of passages within the volcano and the rapid draining of a magma chamber. This changed the stress field in the volcano to trigger extensional faulting in the edifice, as evidenced by the presence of deep (5-6 $\mathrm{km}$ ) earthquakes beneath Loihi's summit. Water chemistry and sonobuoy signals indicated that some of the magma erupted at the time of the RRC. As the chamber drained, the roof slowly collapsed, resulting in the formation of Pele's Pit and faulting of the summit region. The time period required to form the pit is not known, but submersible observations confirmed that both the formation of Pele's Pit and the additional faulting of the summit region had occurred by 7 August. Additional settling of the edifice and partial recharge of the magma chamber continued throughout August as evidenced by the variety of first motions evident in phase $2 c$ events.

\section{Acknowledgments}

We wish to thank David Hill, Jose Pujol, and Martha Savage for insightful and thorough reviews of this manuscript. We are deeply indebted 
to Paul Okubo of the Hawaii Volcano Observatory for his time, data, and guidance. Other members of the HVO staff, notably Jennifer Nakata, Alvin Tomori, and Wil Tanigawa, generously contributed to the initial data processing and offered insights into the challenge of earthquake location. We are grateful to the Hawaii Undersea Research Laboratory for providing us with the OBS. For his excellent piloting of the Pisces V submersible, deployment of the OBS, and insights into Loihi's behavior, we thank Terry Kerby. Conversations with Michael Garcia, David Clague, and Alex Malahoff helped guide the direction the manuscript would take. This article also benefited from critical reviews by Garrett Ito and Julia Morgan. This project was supported in part by National Science Foundation Grant OCE98-18793. J.C.-A. had additional support from a University of Hawaii Geology and Geophysics department fellowship. This is SOEST Contribution Number 5331.

\section{References}

Ben-Zion, Y., and J. R. Rice (1995). Slip patterns and earthquake populations along different classes of faults in elastic solids, J. Geophys. Res. 100, 12,959-12,983.

Bryan, C. J., and P. Cooper (1995). Ocean-bottom seismometer observations of seismic activity at Loihi seamount, Hawaii, Mar. Geophys. Res. 17, 485-501.

Caplan-Auerbach, J., G. Moore, J. Morgan, and F. Duennebier (1998). The internal structure of Loihi seamount, a reflection and refraction study of an undersea volcano (supplement), EOS Trans. AGU 79, 1008.

Chouet, B. (1988). Resonance of a fluid-driven crack: radiation properties and implications for the source of long-period events and harmonic tremor, J. Geophys. Res. 93, 4375-4400.

Chouet, B. A. (1996). Long-period volcano seismicity: its source and use in eruption forecasting, Nature 380, 309-316.

Chouet, B. A., R. A. Page, C. D. Stephens, J. C. Lahr, and J. A. Power, (1994). Precursory swarms of long-period events at Redoubt Volcano (1989-1990), Alaska: Their origin and use as a forecasting tool, $J$. Volcanol. Geotherm. Res. 62, 95-135.

Duennebier, F., N. Becker, J. Caplan-Auerbach, D. A. Clague, J. Cowen, M. Cremer, M. Garcia, F. Goff, A. Malahoff, G. M. McMurtry, B. P. Midson, C. I. Moyor, M. Norman, P. Okubo, J. A. Resing, J. M. Rhodes, K. Rubin, F. J. Sansone, J. R. Smith, K. Spencer, X. Wen, and C. G. Wheat (1997). Researchers rapidly respond to submarine activity at Loihi volcano, Hawaii, EOS Trans. AGU 78, 229-233.

Fehler, M., and B. Chouet, (1982). Operation of a digital seismic network on Mount St. Helen's volcano and observations of long period seismic events that originate under the volcano, Geophys. Res. Lett. 9, 10171020.

Filson, J., T. Simkin, and L. Leu (1973). Seismicity of a caldera collapse: Galapagos islands, 1968, J. Geophys. Res. 78, 8591-8621.

Fornari, D. J., M. O. Garcia, R. C. Tyce, and D. G. Gallo (1988). Morphology and structure of Loihi seamount based on Seabeam sonar mapping, J. Geophys. Res. 93, 15,227-15,238.

Francis, T. J. G. (1974). A new interpretation of the 1968 Fernandina caldera collapse and its Implications for the mid-ocean ridges, Geophys. J. R. Astro. Soc. 39, 301-318.

Garcia, M. O., K. H. Rubin, M. D. Norman, J. M. Rhodes, D. W. Graham, D. W. Muenow, and K. Spencer (1998). Petrology and geochronology of basalt breccia from the 1996 earthquake swarm of Loihi seamount, Hawaii: magmatic history of its 1996 eruption, Bull. Volcanol. 59, 577-592.

Gudmundsson, A. (1998). Formation and development of normal-fault calderas and the initiation of large explosive eruptions, Bull. Volcanol. 60, 160-170.

Hill, D. P., and J. J. Zucca (1987). Geophysical constrains on the structure of Kilauea and Mauna Loa volcanoes and some implications for seismomagmatic processes, in Volcanism in Hawaii, R. W. Decker, T. L. Wright and P. H. Stauffer (Editors), U. S. Geol. Surv. Profess. Pap. 1350, 903-917.
Hirn, A., J. Lepine, M. Apin, and H. Delorme (1991). Episodes of pit-crater collapse documented by seismology at Piton de la Fournaise, J. Volcanol. Geotherm. Res. 47, 89-104.

Julian, B. R. (1998). Non-double-couple earthquakes. I. Theory, Rev. Geophys. 36, 525-549.

Kaufman, K., and L. J. Burdick (1980). The reproducing earthquakes of the Galapagos islands, Bull. Seism. Soc. Am. 70, 1759-1770.

Klein, F. W. (1981). A linear gradient crustal model for south Hawaii, Bull. Seism. Soc. Am. 71, 1503-1510.

Klein, F. W. (1982). Earthquakes at Loihi submarine volcano and the Hawaiian hot spot, J. Geophys. Res. 87, 7719-7726.

Klein, F. W. (1989). User's guide to HYPOINVERSE, a program for VAX computers to solve for earthquake locations and magnitudes, $U$. S. Geol. Surv. Open-File Rept. 89-314.

Klein, F. W., R. Y. Koyanagi, J. S. Nakata, and W. R. Tanigawa (1987). The seismicity of Kilauea's magma system, in Volcanism in Hawaii, R. W. Decker, T. L. Wright and P. H. Stauffer (Editors), U. S. Geol. Surv. Profess. Pap. 1350, 1019-1185.

Kong, L. S. L., P. G. Okubo, G. F. Moore, F. K. Duennebier, S. C. Webb and W. Crawford (1997). Crustal structure of Kilauea's south flank and Loihi seamount (abstracts with programs), Geol. Soc. Am. 29, 23.

Koyanagi, R. Y., W. R. Tanigawa, and J. S. Nakata (1988). Seismicity associated with the eruption, in The Puи Oo Eruption of Kilauea Volcano, Hawaii: Episodes 1 through 20, January 3, 1983, through June 8, 1984, E. W. Wolfe (Editor), U. S. Geol. Surv. Profess. Pap. 1463, $183-235$

Lahr, J. C., B. A. Chouet, C. D. Stephens, J. A. Power, and R. A. Page (1994). Earthquake classification, location, and error analysis in a volcanic environment: implications for the magmatic system of the 1989-1990 eruptions at Redoubt Volcano, Alaska, J. Volcanol. Geotherm. Res. 62, 137-151.

Malahoff, A. (1987). Geology of the summit of Loihi submarine volcano, in Volcanism in Hawaii, R. W. Decker, T. L. Wright and P. H. Stauffer (Editors), U. S. Geol. Surv. Profess. Pap. 1350, 133-144.

McNutt, S. (1986). Observations and analysis of B-type earthquakes, explosions and volcanic tremor at Pavlof volcano, Alaska, Bull. Seism. Soc. Am. 76, 153-175.

Okubo, C., and S. J. Martel (1998). Pit crater formation on Kilauea volcano, Hawaii, J. Volcanol. Geotherm. Res. 86, 1-18.

Pitt, A. M., and D. P. Hill, (1994). Long-period earthquakes in the Long Valley Caldera region, eastern California, Geophys. Res. Lett. 21, 1679-1682.

Reasenberg, P. A., and D. Oppenheimer (1985). FPFIT, FPPLOT and FPPAGE: FORTRAN computer programs for calculating and displaying earthquake fault plane solutions, U. S. Geol. Surv. Open-File Rept. 85-739.

Simkin, T., and K. A. Howard (1970). Caldera collapse in the Galapagos islands, Science 169, 429-437.

Smith, J. R., F. K. Duennebier, A. Malahoff, and G. Parker (1997). Deeptow multibeam bathymetric study of Loihi seamount, Hawaii (supplement), EOS Trans. AGU $\mathbf{7 8} 648$.

Tilling, R. I., and J. J. Dvorak (1993). Anatomy of a basaltic volcano, Nature 363, 125-133.

Walker, G. P. L. (1988). Three Hawaiian calderas: an origin through loading by shallow intrusions? J. Geophys. Res. 93, 14,773-14,784.

Wyss, M. (1973). Toward a physical understanding of the earthquake frequency distribution, Geophys. J. R. Astr. Soc. 31, 341-359.

Yamasato, H., T. Yokota, and S. Kashiwabara (1991). Earthquake swarm and volcanic tremors off Eastern Izu Peninsula in 1989: spectral investigations and characteristics of waveforms, J. Phys. Earth 39, 79-92.

Department of Geology and Geophysics

University of Hawaii

Honolulu, Hawaii

Manuscript received 21 December 1999. 